\title{
Risk Factors of Esophageal Adenocarcinoma at Karachi, Pakistan
}

Humera Jabeen, ${ }^{1}$ Saba Hassan Shamim, ${ }^{2}$ Farheen Danish, ${ }^{2}$ Lubna Avesi, ${ }^{2}$ Aneela Tabassum, ${ }^{3}$ Amin Fahim ${ }^{4}$

\begin{abstract}
Background: The esophagus is exposed to various factors being on the beginning of the gastrointestinal tract. Pathologies of esophagus vary from epithelial erosions to deep muscular involvement and from mild inflammation to cancers.

Objective: To determine the risk factors like gender, smoking and gastro esophageal reflux disease for esophageal adenocarcinoma.

Methodology: This comparative cross sectional study was carried out at Pathology department of Al-Tibri Medical College and Dow University of Health Sciences, Karachi, fromApril to September, 2018. After ERC approval 88 human subjects were selected through non-probability sampling using inclusion and exclusion criteria 22 subjects as controls (group-I) and 22 individuals withBarrett's esophagus (Group-II), 22 patients with dysplasia(Group-III) and 22 known patients of esophageal adenocarcinoma (Group-IV). Risk factors like age, gender involvement, smoking and gastroesophageal reflux disease (GERD) were evaluated among these groups in terms of frequency and percentage, mean and standard deviation.

Results: Overall males were $70(79.55 \%)$ and females were $18(21.45 \%)$, similar fractions were observed as smokers and non-smokers and GERD but age ranged different in different study groups and $40(45.54 \%)$ belonged to age range of 51-60 years. Mean age was $43 \pm 6,56 \pm 2,61 \pm 4$ and $63 \pm 3$ years, for groups I, II, III and IV respectively (p=0.00). Sex $(\mathrm{p}=0.1)$ and smoking $(\mathrm{p}=0.3)$ were not significantly associated with esophageal adenocarcinoma whereas, age $(\mathrm{p}=0.00)$ and GERD status $(\mathrm{p}=0.00)$ were significantly associated with esophageal adenocarcinoma in this study.

Conclusion: We found that age, gastroesophageal reflux disease were significantly associated with development of adenocarcinoma of esophagus in our study.

Key words: Dysplasia, GERD, Esophageal Adenocarcinoma, Sex, Smoking

Article Citation: Jabeen H, Shamim SH, Danish F, Avesi L, Tabassum A, Fahim A. Risk Factors of Esophageal Adenocarcinoma at Karachi, Pakistan. JSZMC 2020;11(2):03-07. DOI: https://doi.org/10.47883/jszmc.v11i2.78
\end{abstract}

\section{Introduction}

Esophagus is a part of upper gastro intestinal tract starting from pharynx up to upper end of stomach. Esophagus is lined by non-keratinized stratified squamous epithelium. Histologically, it consist of four layers including mucosa (epithelial layer, lamina propria and muscularis mucosa) sub mucosa, muscularis layer and adventitia. ${ }^{1}$ Some conditions like prolong acid reflux, smoking, obesity, alcohol consumption and gastro esophageal reflux disease (GERD) can cause replaced squamous epithelium(normal) with columnar epitheliumof intestinal type(abnormal). When this condition is identified endoscopically and biopsy also shows the goblet cell it is labeled as Barrett's esophagus (BE). ${ }^{2}$ A study from Asian country reported that prevalence of Barrett's is $5.9 \%$ in India and in Iran it was reported as $0.2 \%$, while in Japan it was $0.2 \%$ in long-segment Barrett esophagus and $19.7 \%$ in short-segment Barrett esophagus respectively in a study from single center. ${ }^{3}$ Worldwide incidence of Barrett's esophagus is increasing dramatically it is estimated to be $0.5 \%$ to $0.2 \%$. Among all risk factors GERD is top one cause of Barrett's esophagus and prevalence of Barrett's esophagus is estimated around 5 to $15 \%$ in patient with GERD. ${ }^{4}$ Carcinoma of the esophagus is considered 6th leading etiology for death among all cancers apart from being 8th common most cancer round the globe. Globally five year survival time is ranging from $15 \%$ to $25 \%$. $^{5}$ Top ten malignancies reported in Pakistan from January 2016 to December 2016 esophagus cancer comes at 4th number $(4.69 \%)$ in malignancies seen amongst all age-groups, both sexes. ${ }^{6}$ Adenocarcinoma is reported as one of the complication of Barrett's esophagus

1. Department of Pathology, Peshawar Medical College, Peshawar, Pakistan.

2. Department of Pathology, Dow International Medical College, Dow University of Health Sciences, Karachi, Pakistan.

3. Department of Pathology, Al-Tibri Medical College, Karachi, Pakistan.

4. Department of Pathology, Isra University, Hyderabad, Pakistan.

Correspondence: Dr. Humera Jabeen, Senior Lecturer, Department of Pathology, Peshawar Medical College, Peshawar, Pakistan.

Received: $24-03-2020$

Revised: $18-04-2020$ 
with incidence in Barrett's esophagus patient as $0.5 \%$. In early 20 th century esophageal adenocarcinoma was reported as a major esophageal cancer in 2014. ${ }^{7}$ Prolonged GERD may lead to metaplasia which further progress to dysplasia and then esophageal adenocarcinoma. Dysplasia is classified into; Indefinite for dysplasia, a condition of ulceration or inflammation in which to differentiate between regeneration and dysplasia is difficult, Low-grade dysplasia (LGD), a condition in which significant lack of surface maturation with atypical nuclei limited to the basal portion of the cell cytoplasm while preserving crypt architecture, High grade dysplasia (HGD), atypical cell involve full thickness of epithelium cell showing pleomorphism, atypical mitoses, and increased cytological and/or architectural complexity. ${ }^{8}$ To prevent the progression of Barrett's esophagus to dysplasia early diagnosis has important role in high risk patients. It also helps to plan available treatment modalities. This can be done by making risk score comprising of clinical, histological and endoscopic variables. Biomarker representing early changes in Barrett's esophagus has developed a new platform for early diagnosis and prevention in Barrett's esophagus progression to dysplasia.' The results of this study would be adding knowledge regarding the causes of the esophageal carcinoma and will provide basis for awareness in our community to prevent or delay the development of esophageal adenocarcinoma. This study was conducted to determine different risk factors like age, gender, smoking and GERD, which may result into the development of adenocarcinoma of the esophagus.

\section{Methodology}

This comparative cross sectional study was conducted after Ethical Review Committee approval from April to September, 2018 and 88 diagnosed biopsy samples, were selected through non-probability sampling using inclusion and exclusion criteria and data was collected after written consent from participants.

Sample size was calculated by taking confidence level at $95 \%$ (1.96), the probability of an event that is occurring as $6 \%$ and the margin of sampling error taken at 5\%.2 Study was carried out at the Department of Pathology at Al-Tibri Medical College and Dow University of Health Sciences, Karachi. The distribution of study population groups was as; 22 subjects as normal controls with stratified squamous epithelium (group-I) and 22 individuals with Barrett's esophagus (Group-II), 22 patients with dysplasia (Group-III) and 22 known patients of esophageal adenocarcinoma (Group-IV). Required information was acquired on proforma while pathological diagnosis was made by the concerned histopathologists of Dow University Laboratory. Risk factors like gender involvement, smoking and GERD were evaluated among these groups in terms of frequency and percentage while mean and standard deviation and ranges were calculated for age on 22nd version of SPSS using as statistical tool. $\mathrm{P}$ value of less than 5\% was taken as significant.

\section{Results}

Majority of our study patients 40 (45.54\%) belonged to age group of 51-60 years, followed by 25 (28.40\%) with 61-70 years age group, 71-80 years 12 $(13 \%), 41-50$ years $6(6.8 \%)$ and $31-40$ years 5 $(5.6 \%)$, with a mean age $43.09 \pm 6.52,56.63 \pm 2.64$, $61.68 \pm 4.23$ and $63.90 \pm 3.80$ for groups I, II, III and IV respectively $(\mathrm{p}=0.00)$. There were 88 study subjects out of which $70(79.55 \%)$ were males and 18 $(21.45 \%)$ were females similarly $70(79.55 \%)$ of the study participants were found to be smokers while 18 (21.45\%) were non-smokers whereas, 14 (64\%) cases with gastro esophageal reflux disease (GERD) in Group I, in group II there were 19 (86\%) cases presented with gastro esophageal reflux disease.

Table-I: Study groups and gender distribution

\begin{tabular}{|l|c|c|c|c|c|}
\hline GERD & Group-I & Group-II & Group-III & Group-IV & Total \\
\hline GERD & $14(64 \%$ & $19(86 \%)$ & $17(77 \%)$ & $18(81.8 \%)$ & $70(79.55 \%)$ \\
\hline No-GERD & $8(36.4 \%)$ & $3(13.6 \%)$ & $5(22.7 \%)$ & $4(18.2 \%)$ & $18(21.45 \%)$ \\
\hline Total & 22 & 22 & 22 & 22 & $88(100 \%)$ \\
\hline P value & \multicolumn{5}{|l|}{0.00} \\
\hline
\end{tabular}


Table-II: Smoking status among various study groups

\begin{tabular}{|l|c|c|c|c|c|}
\hline Smoking status & Group-I & Group-II & Group-III & Group-IV & Total \\
\hline Smokers & $14(63.6 \%)$ & $18(81.8 \%)$ & $18(81.8 \%)$ & $18(81.8 \%)$ & $70(79.55 \%)$ \\
\hline Non-Smokers & $8(36.4 \%)$ & $4(18.2 \%)$ & $4(18.2 \%)$ & $4(18.2 \%)$ & $18(21.45 \%)$ \\
\hline Total & 22 & 22 & 22 & 22 & $88(100 \%)$ \\
\hline P value & \multicolumn{5}{|l}{0.3} \\
\hline
\end{tabular}

Table-III: Study groups and gender distribution

\begin{tabular}{|l|c|c|c|c|c|}
\hline Sex & $\begin{array}{c}\text { Group-I } \\
\text { (Normal) }\end{array}$ & $\begin{array}{c}\text { Group-II } \\
\text { (Barret,s } \\
\text { Esophagus) }\end{array}$ & $\begin{array}{c}\text { Group-III } \\
\text { (Dysplasia) }\end{array}$ & $\begin{array}{c}\text { Group-IV } \\
\text { (Adenocarcinoma) }\end{array}$ & Total \\
\hline Male & $16(72.7 \%)$ & $19(86.4 \%)$ & $17(77.3 \%)$ & $18(81.8 \%)$ & $70(79.55 \%)$ \\
\hline Female & $6(27.3 \%)$ & $3(13.6 \%)$ & $5(22.7 \%)$ & $4(18.2 \%)$ & $18(21.45 \%)$ \\
\hline Total & 22 & 22 & 22 & 22 & $88(100 \%)$ \\
\hline P value & \multicolumn{5}{|c|}{0.2} \\
\hline
\end{tabular}

In group III, there were 17 (77\%) cases presented with gastro esophageal reflux disease, and group IV showed $18(81 \%)$ cases with gastro esophageal reflux disease. Results with reference to sex, smoking and GERD status are shown in table I, II and III.

\section{Discussion}

There are numerous factors which lead to increased risk of developing esophageal cancer in a person and it includes; tobacco use orally as chewing or in the form of smoking such as cigarette or sheesha, alcohol use, gastroesophageal reflux disease (GERD), Barrett's esophagus (BE) which results from condition which affects the lower part of the esophagus and elderly men which are obese. There is also some variation as white men have higher risk of adenocarcinoma whereas, colored skin men and especially Asian men have more risk of squamous cell carcinoma. This suggest genetic and community wise variation which may predispose some one to risk of developing esophageal carcinoma. So current study reveals the evidence on risk factors of adenocarcinoma esophagus among Pakistani population that is asian colored skin persons.

A study conducted by Westhoff B et al, with the aim to determine the frequency of BE patients presenting for a first endoscopic evaluation with GERD as the indication showed that a total of 378 consecutive patients with GERD, $50(13.2 \%)$ have BE. However, there was no significant difference between patients with long segment barrets esophagus and short segment barrets esophagus, with respect to age, gender, ethnicity, BMI, and
GERD symptom duration. This study Westhoff B et al was conducted on population of Indian origin agrees with age related findings of the current study. ${ }^{10}$ Whereas study from Japan conducted by Yuji Tamagawa et al (2016)on normal along with Barrett esophagus population and found the mean age as $63.9 \pm 9.8$ years in patients of barrett esophagus that is also consistent with our study results which is found to be $63.90 \pm 3.80$ years. ${ }^{11}$ The study of Whitson et al showed that females were $25 \%$ and $75 \%$ were male which was consistent with our study findings with males as $79.55 \%$ in majority and females as $21.45 \%$ of the study subjects. ${ }^{12}$ Another study by Oberg S et al reported that the gastric adenocarcinoma was found to be present more in males that was $73.77 \%$ in comparison to females in which it was $22.33 \%$ ) these study findings are also supportive and consistent to our study results showing adenocarcinoma present in $81.8 \%$ males while $18.2 \%$ females. ${ }^{13}$ The literature shows a variable pattern of occurrence of carcinomas worldwide. In a study conducted in Kolkata with the objective risk factors in gastric adenocarcinoma, male to female ratio was 2.89:1. Gastric adenocarcinoma was found in $61(87.1 \%)$ cases; $22.9 \%$ were of intestinal type and $77.1 \%$ of diffuse type and only IM was found in $9(12.9 \%)$ cases and they showed that there is a disparity between genders while considering adenocarcinoma that is also favors our findings. ${ }^{14}$ Current study found tobacco smoking prevalent in all study groups as $63.6 \%$ in group, $81.8 \%$ in group II, while $81.8 \%$ in group III and $81.8 \%$ of subjects in group IV with an overall smokers of $79.55 \%$ in study participants that increases the risk for the development of gastric cancer which is in accordance with a study from China involving a population of 3000 individuals, 
reported that the dysplasia and metaplasia chances are doubled in smokers. ${ }^{15}$ A meta-analysis also demonstrated that there is increased risk of gastric cancer development among smokers by 1.5-1.6 times in contrast to non-smokers that falls in consistency to our observations. ${ }^{16,17}$ Gastroesophageal reflex disease may get complicated into bleeding leading to anemia, ulceration leading to dysphagia, strictures and malignancy leading to weight loss. ${ }^{18}$ Patients having long term GERD are at greater risk of developing barrett's esophagus (intestinal metaplasia) where the normal epithelial lining (squamous epithelium) gets replaced with an abnormal one (columnar epithelium) in response to higher and constant HCL exposure. ${ }^{19}$ In a previous study, which collected evidence that whether using demographic characteristics and alarm symptoms can accurately predict cancer in patients with dyspepsia in Iran, they reported that in a relatively larger sample size of 2,847 patients with dyspepsia participated in this study, of whom 87 (3.1\%) had upper GI malignancy and esophageal or gastric cancers in patients with dyspepsia was associated with older age, being male, and symptoms of weight loss and vomiting and barrett's esophagus has the potential for progressive conversion into adenocarcinoma of the esophagus, so its earlier diagnosis of prime importance for preventing as well as managing these transformation of malignant nature. ${ }^{20} \mathrm{We}$ observed that $79.55 \%$ of our study participants having GERD while only $21.45 \%$ were found without these symptoms. Various previously published research studies show the GERD prevalent in $10 \%-20 \%$ of Western population while $5 \%$ in Asian populations and $23.5 \%$ to 45.4\% among the Saudi Arabian population, the difference might be due to regional, cultural and life style differences between various studies along with the specific and non- specific study population as well as the sample size studied. ${ }^{21} \mathrm{We}$ only focused on 3 common factors and could not evaluate more risk factors due tour limited time duration as well as the limited resources that were the weakness of our study. We recommend a larger scale research based on multiple parameters including biomarkers, biopsies and genetics along with social and environmental factors so that multi-dimensional approach can be developed for early detection, prevention and management of this lethal condition.

\section{Conclusion}

We found that age, gastroesophageal reflux disease were significantly associated with development of adenocarcinoma of esophagus in our study, however in our study gender and smoking were not significantly associated with adenocarcinoma of esophagus.

\section{Author Contribution}

HJ: Conception of work, design of work and revising. SHS: Design of work, Acquisition and analysis of data and drafting. FD \& AF: Interpretation of data and revising. LA \& AT: Interpretation of data, revising.

All authors critically revised and approve its final version.

\section{Conflict of interest: None \\ Resources of funding: Self}

\section{References}

1. Kou B, UrmaD. Esophagus anatomy and development. Goyal and shaker GI Motility online 2006.doi:10.1038.

2. Singh S, Sharma AN, MH MuradButtar NS, Hashem B, El Serag, Katzka DA et al. Central adiposity is associated with increased risk of esophageal inflammation, metaplasia, and adenocarcinoma: a systematic review and meta-analysis. Clin Gastroenterol Hepatol2013;11(11): 1399-1412.

3. Amano Y, Kinoshita Y. Barrett esophagus perspective on its diagnosis and management in Asian population. GastroenterolHepatol2008;4(1):45-53.

4. RM Thomas, AA Julian, NJ Shaheen. Epidemiology of Barrett's Esophagus and Esophageal Adenocarcinoma. Gastroenterol Clin North Am 2015; 44(2): 203-31.

5. Arnal MJD, ArenasAF, ArbeloaAL. Esophageal cancer: Risk factors screening and endoscopic treatment in Western and Eastern countries. World J Gastrol 2015; 21(26): 7933 43.

6. Mahmood S, Faraz R, Yousaf A, Quader AU, Asif H, Atif A et al. Annual Cancer Registry Report-2016, of The Shaukat Khanum Memorial Cancer Hospital \& Research Center, Pakistan. 2016:1-14.

7. Choi TW, Emond JM, Rabinovitch SP, Ahn J, Upton PM, Westerhoff M. Indefinite for Dysplasia" in Barrett's Esophagus: Inflammation and DNA Content Abnormality are Significant Predictors of Early Detection of Neoplasia. Clin and Translatl Gastrols 2015; 6(3):e81

8. GW Falk. Current Management of Low-Grade Dysplasia in Barrett Esophagus. Gastroenterol Hepatol 2017; 13(4): 22125.

9. Azodi MZ, RT Mostafa, H Hadi, RR Sara DS. Introducing biomarker panel in esophageal, gastric, and colon cancers; a proteomic approach. Gastroentrol Hepatol 2015; 8(1): 6-18.

10. Westhoff B, Brotze S, Weston A, McElhinney C, Cherian R, Mayo MS, et al. The frequency of Barrett's esophagus in high-risk patients with chronic GERD. Gastrointestinal Endoscopy 2005; 61(2): 226-31. 
11. Yuji Tamagawa, NorihisaIshimura, Goichi Uno, Masahito Aimi, Naoki Oshima. Bile acids induce Deltalike 1 expression via $\mathrm{Cdx} 2$-dependent pathway in the development of Barrett's esophagus. Laboratory Investigation 2016; 96: 325-337.

12. Whitson BA, Groth SS, Li Z, Kratzke RA, Maddaus MA. Survival of patients with distal esophageal and gastric cardia tumors: a population-based analysis of gastroesophageal junction carcinomas. J Thorac Cardiovasc Surg 2010; 139(1): 43-8.

13. Oberg S, Wenner J, Johansson J, Walther B, Willén R. Barrett esophagus: risk factors for progression to dysplasia and adenocarcinoma. Ann Surg 2005; 242(1): 49-54.

14.Mandal PK, Chakrabarti S, Ray A, Chattopadhyay B, Das S. Mucin histochemistry of stomach in metaplasia and adenocarcinoma: An observation. Indian Journal of Medical and Paediatric Oncology 2013; 34(4): 229-33.

15. Conio M, Filiberti R, Blanchi S, Ferraris R, Marchi S, Ravelli P, et al. Risk factors for Barrett's esophagus: a case-control study. Int J Cancer 2002; 97(2): 225-9.
16. Humans IWG on the E of CR. Tobacco Smoke and Involuntary Smoking. International Agency for Research on Cancer; 2004.

17. Jencks DS, Adam JD, Borum ML, Koh JM, Stephen S, Doman DB. Overview of Current Concepts in Gastric Intestinal Metaplasia and Gastric Cancer. Gastroenterol Hepatol(NY). 2018; 14(2): 92-101.

18. Katz PO, Gerson LB, Vela MF. Guidelines for the diagnosis and management of gastroesophageal reflux disease. Am J Gastroenterol 2013; 108:308-328.

19. Clarrett DM, Hachem C. Gastroesophageal Reflux Disease (GERD). Mo Med 2018; 115(3): 214-218.

20. Khademi H, Radmard AR, Malekzadeh F, Kamangar F, Nasseri-Moghaddam S, Johansson M, et al. Diagnostic accuracy of age and alarm symptoms for upper GI malignancy in patients with dyspepsia in a GI clinic: a 7year cross-sectional study. PLoS One 2012; 7: e39173.

21.Kariri AM, Darraj MA, Wassly A. Prevalence and risk factors of Gastroesophageal Reflux Disease in Southwestern Saudi Arabia. Cureus 2020; 12(1):e6626. doi:10.7759/cureus.6626 